\title{
Privacy and trust in the Information Society
}

\author{
Dirk van Rooy \\ European Commission, DG Information Society and Media
}

Disclaimer: Any views or opinions presented are not necessarily those of the European Commission and remain the sole responsibility of the author.

\section{Extended synopsis}

The Directorate-General Information Society and Media, part of the European Commission, supports the development and use of information and communication technologies (ICT) for the benefit of all citizens and for underpinning European competitiveness and growth. Its objective is to stimulate the continued development of an all-inclusive information society, and the assurance of trust and security is pivotal to this development. Security and privacy protection are moving targets, and bringing trust into the networked society is an open-ended, permanent and multistakeholder endeavour.

With the daily emergence of new personalised services, we face a permanently changing threat landscape. The ICT Programme managed by DG INFSO includes key research activities supporting the development of identity management and privacy enhancing technologies to keep abreast of these mutating challenges. However, technology alone is not enough; it has to go hand in hand with other measures, including legislation and policy. Competitive markets and business opportunities should lead to a strong business drive, and last, but certainly not least, there needs to be informed and responsible user behaviour and strong well-informed user demand.

To address the above challenges, the European Union has established a well structured set of measures, including a comprehensive regulatory baseline and an ambitious research programme to stimulate technology development and uptake. These three activities - regulation, research and the promotion of wider use - form the pillars for the creation and promotion of a competitive, inclusive and trustworthy European information society and knowledge economy.

The conference of today, IDMAN 2007, offers a platform for exchanging views on the pivotal role that identity management technologies play in this context, and how these technologies can be used to enhance and protect privacy in the information society. Such initiatives are important to uncover future requirements for research and technological development in this area. The outcome of such exchanges adds to the technology pillar of providing a more secure, trustworthy and inclusive information society in the future.

The knowledge society under creation is a great step forward for mankind. It enables people to use information wherever and whenever they need it, adapted to their personal interests. Every day more and more people, organisations and devices 
get connected to the Internet. They bring more linkable information and business, and more communication. The trust and confidence of end-users in ICT services are crucial in order for this evolving information society to remain successful. Employees connect remotely to their organisation. Consumers leave personal information almost everywhere, and these data are stored - sometimes for a life-time - on interconnected systems everywhere. Collaborative work beyond company and organisational boundaries, across the globe, is becoming a daily thing.

Identity management with proper privacy protection and user empowerment is of key importance for creating the necessary trust for a continued development of the digital society. On May 2nd, 2007, the Commission adopted a policy on Promoting Data Protection by Privacy Enhancing Technologies (PETs), part of a bouquet of regulatory and policy initiatives in the domain of ensuring a trustworthy all-inclusive knowledge society. This policy underlines that privacy is a fundamental right implemented in EU directives and Member States' legislation. However, this might be insufficient when personal data are disseminated worldwide, and when - in sync with the development of new ICT services - new risks arise. The PETs Communication calls for follow-up actions, including stepping up research and development, promoting the use of PETs by data controllers, standardization, and raising consumer awareness to facilitate informed choice making. The PETs information pack is available at ec.europa.eu/information_society/activities/privtech.

Other initiatives aiming at increasing security in the networked society include the adoption of a strategy for a secure information society (2006). The essential elements of this European strategy are dialogue, partnership and empowerment amongst the key stakeholders. In 2006 the Commission adopted a policy on fighting spam, spyware and malicious software. Another example is RFID, a technology that offers great economic potential, but at the same time is an attractive target for attackers and potentially a risk to privacy. The Commission has organised a broad consultation and adopted a policy that puts particular emphasis on security and privacy. As we do not only need protection and prevention, but also deterrence, the Commission adopted in 2007 a policy on cybercrime.

It is clear that most technology can be used in different ways, for example by states that want to control and supervise their people. But let us not only look at possible abuse of information by states, but also by private data controllers, for example companies collecting and using identity and profiling data for their own profit, without much regard for privacy and the personal sphere. ICT systems do not need to store personal data attributes for running application services together with the identity data to which the attributes belong. The linkage of identity data with profiling and other personal data attributes can be controlled by the user. There is a need for ID management standards at the meta level that enable controlled separation from application management, and the principles of minimum transfer of identifiable data should be implemented.

On the research side the EU has been funding research and development in the area of ICT trust and security for many years. As part of the $6^{\text {th }}$ RTD Framework Programme (2002-2006) about 35 projects centred in this area were funded, amounting to about $€ 145$ million funding contribution. We are currently in the initial 
phase of launching new projects under the ICT Programme of FP7 (2007-2013). Further information can be found at: http://cordis.europa.eu/fp7/ict/security.

The evolving knowledge society is a major step forward for mankind. It enables people to use information wherever and whenever they need it, adapted to their personal interests. We should ensure that this new society is a society for all, a society built on confidence and trust. 